\title{
Pre-service teachers linking their metalinguistic knowledge to their practice: a functional approach
}

Anne Thwaite

\author{
Correspondence: \\ a.thwaite@ecu.edu.au \\ School of Education, Edith Cowan \\ University, Bradford St, Mt Lawley \\ 6050, Australia
}

\begin{abstract}
Existing work in Anglophone countries has raised concerns regarding teachers' knowledge about language (KAL); this may well be an issue in other countries also, with notable exceptions such as Finland. In Australia, with the introduction of the new Australian Curriculum, the question of teacher KAL has become crucial. Teachers, both practising and pre-service, generally have some knowledge about language as an object, usually including the text structures of particular school genres and information about sentence structure and word classes. This knowledge may be based on traditional grammar and may not be well applied above the sentence level. Teachers may also have an intuitive knowledge of discourse structures and are beginning to reflect on their own discourse using understandings of dialogic teaching.

This paper provides an example of how first-year pre-service teachers (PSTs) were introduced to KAL at both the grammatical and the discourse levels, as part of an introductory unit on spoken language. A range of approaches was used, including a functional view of discourse. The PSTs then applied their KAL by putting it into a context that was meaningful for them: discussing their own practice. The paper gives an illustration of some of the work they produced that demonstrates their emerging understandings.
\end{abstract}

Keywords: KAL; Pre-service teachers; Classroom discourse analysis

\section{Introduction}

There is a growing body of research in Anglophone countries on the knowledge about language (KAL) of both practising teachers and pre-service teachers (PSTs). The present author has found it useful to use the acronym KAL when talking with teachers and PSTs. If the term 'grammar' is used, teachers tend to assume that this means sentence-level grammar, or even just word classes, whereas KAL has the potential to cover a broader scope. The Hallidayan term 'grammatics', as used for example by Macken-Horarik (2012), has more of a technical flavour that may be discouraging for some teachers, even though it is an accurate description.

With the introduction of the new Australian Curriculum (AC), the question of teacher KAL has become crucial. While some of the literature, for example, Harper and Rennie (2009) from Australia and Jeurissen (2012) from New Zealand, emphasises teachers' lack of KAL, it is possible to improve pre-service teachers' knowledge in this 
area, as Jeurissen demonstrates. In the present author's experience, even a three-week intervention was shown to improve PSTs' knowledge at the word and sentence level (Thwaite, 2008). In a four-year program there is more scope for development: (Thwaite \& Rivalland 2009)) describe a unit for fourth year pre-service and practising teachers which focused on discourse analysis, and which they were then able to apply to analysing their own practice.

Scholars such as Myhill et al. (2013) have demonstrated that teachers' 'applied' knowledge is more significant than their knowledge of language as object. The study by Myhill et al. focused on middle school teachers and the teaching of writing. The question under investigation in the present study is whether an introductory unit for pre-service teachers, involving word classes and simple functional discourse analysis, can be used by them as a basis for reflecting on their own practice and thus applying their KAL. In referring to functional discourse analysis, we are of course assuming that the function of utterances, as well as their form, is a fundamental part of KAL. Indeed, Martin (2007), p. 57) suggests an even broader scope for KAL, including, 'register, discourse semantics, lexicogrammar, graphology and image grammar'.

\section{Background}

The participants in the study were pre-service teachers in a Bachelor of Education (Primary) program. This is a four-year program to prepare graduates to teach children aged approximately five to eleven years. In the focus year for this study, 2010, 198 PSTs enrolled in the first-year unit Language Education 1, with 164 still enrolled at the end of semester. The PSTs in the Bachelor of Education (Primary) enter either directly from school or through several other pathways. Whichever their method of entry to the course, it cannot be assumed that they have any explicit metalinguistic knowledge (here glossed as Knowledge About Language, or KAL), unless they were educated outside Australia. (See Thwaite, 2008, for evidence from one cohort of these PSTs.) This situation may eventually change with the introduction of the new Australian Curriculum (AC), currently being implemented throughout the nation. There is some concern that teachers may not be ready to teach the Language strand of the $A C$, due to their lack of explicit KAL.

This paper will describe one method of introducing PSTs to KAL in contexts that were meaningful to them, and the extent to which they were able to use this knowledge to reflect on their own teaching. Samples of their assignments will be used to illustrate how they integrated their KAL into their reflections. In this way, we can see how their knowledge is contextualised; quizzing them about specific items of KAL would not reveal this. As the aim is to demonstrate the potential of this method, the best assignments were selected, and are reproduced with the permission of the PSTs.

\section{Methods}

The paper will describe the participants (PSTs), the teaching materials used, the linguistic analyses to which the PSTs were introduced and the outputs (assignments) from the PSTs, indicating the extent to which they incorporated the KAL into their existing knowledge and practice. 


\section{The participants}

As mentioned above, the participants in the study were PSTs studying the first-year unit Language Education 1. There were 198 enrolled at the beginning of semester in the focus year, 2010, with 164 still enrolled at the end of semester. Of these, 84 (51\%) completed a unit evaluation survey, the results of which are discussed here. The assignments illustrated here are the best ones from the unit (as judged by the grades awarded by the tutors), representing the work of six students.

\section{Place of the unit in the program}

The unit, Language Education 1, was one of four compulsory Language and Literacy units in the Bachelor of Education (Primary) program. In keeping with the Mode continuum (Derewianka 1991), the program commenced with spoken language in Language Education 1, before moving to reading and writing in the following units. We also followed the premise that by the age of five children have mastered the structure of their mother tongue (Halliday 1975), and that what they need to do is expand their repertoire of registers to function effectively in school and other contexts outside their home and community: 'The child will be a more effective communicator at certain times than others. This is because they will have had greater experience in some contexts ... than others' (Painter 1985, p. 44). Thus the unit emphasised the functions of the language used by primary-school children, rather than going into detail about language learning from birth.

\section{Outline of the unit}

The content of the 12-week unit covered the following areas:

1. Language diversity and socio-cultural influences on language.

2. Learning about language:

- Theories of language learning;

- Structure and function of language;

- Language use in a variety of contexts.

3. Teaching Language and supporting children's spoken language in different contexts.

4. Moving to Literacy: the relationship between spoken language and literacy.

\section{The assignment}

The highlight of the unit was visits to local primary schools that enabled the PSTs to collect data for an assignment that focused on their use of language with the children. PSTs needed to plan two contrasting activities so they could compare the language of each visit.

\section{Description of the assignment}

In the assignment the PSTs needed to plan, implement and reflect on two spoken language activities that enabled children to use language for different purposes. The activities were not to involve reading or writing, and the second activity needed to have a different purpose to the first. Each of the activities was conducted on a separate school visit of approximately one hour, where the PSTs worked with a small group of children in the school playground. With the school's permission, the PSTs audio-recorded their interactions, and later transcribed them for the purposes of their assignment. 
In the assignment the PSTs described the activities they had designed and the different types of language associated with each of these activities. They also discussed how their own language, and the activities themselves, supported the children's language use. It was suggested that they could compare the two visits if they wished. The final part of the assignment was a reflection on the success of the activities, considering the language, strategies and resources used.

The questions that the PSTs used to frame their discussion were adapted from Derewianka (1992). Perceptive PSTs realised that the questions were grouped according to the Register variables of Tenor, Field and Mode (Derewianka 2011, p.6). The PSTs had been introduced to the Register variables by showing them examples of transcripts of classroom talk from across the curriculum where changes in Field, Mode and Tenor were reflected in the discourse. In particular, discussion questions about Field were related to their knowledge of word classes, the 'content words' (nouns, verbs, adjectives and adverbs) making up the vocabulary that carried the Field. In relation to Tenor, PSTs were also introduced to Speech Function (Derewianka 2011, pp. 110-114), enabling them to identify Statements, Questions, Commands and Offers, and to examine the form in which these functions were expressed.

The discussion questions for the assignment included the following ones related to the Register variables:

- How would you describe the relationship between you and the children? (Tenor)

- Did you scaffold the development of the topic, and how? (Field)

- How was the talk related to the activities the children were doing? (Mode)

The questions also included the following, more general, ones:

- Were you a facilitator or a controller?

- Did you focus on children's meanings, or on something else?

- Did the talk extend children's thinking?

- Did you encourage peer interaction and risk taking?

- Was the role of 'expert' shared? (This last question relates to the Primary Knower rôle in Exchange Structure Theory: see below.)

\section{Discussion of the assignment}

In discussing the assignment with the PSTs, we emphasised that their activities should not involve reading or writing. Even though the whole unit was about spoken language, some of the PSTs seemed to think that any school activity should involve the written mode. For our school activities it was particularly important not to involve reading or writing, as some of the children we worked with were not yet literate in English. The PSTs were introduced to some wordless picture books that they could use with the children so they would not be distracted by the written text.

\section{Frameworks for analysis}

As well as Derewianka (1992) questions exemplified above, we introduced the PSTs to two other frameworks of analysis that they could use to reflect on their interactions with the children: 
(1) Tough's children's language functions and teacher dialogue strategies (Tough 1977), inspired by the work of Halliday, such as Halliday (1975).

(2) Furniss and Poulton's (1991) framework, which consists of a list of questions about various aspects of classroom discourse, with an emphasis on turn-taking and dynamic moves.

We also introduced the PSTs to the concept of 'primary knower' from Berry's Exchange Structure (Berry 1981a, Berry 1981b, Berry 1981c), elaborated in the work of Ventola (1987). As well as this, we showed the PSTs classroom transcripts with examples of 'interactive trouble', an idea derived from Conversation Analysis (Ludwig \& Herschell, 1996; Freebody \& Ludwig, 1998). For their assignments the PSTs chose concepts from the above analyses, selecting those that they thought were most relevant to their own data. This had the two advantages of preventing them from simply mechanically applying a framework of analysis, and giving them a sense of ownership over their data and analysis.

\section{Tough's functions and strategies}

The PSTs were introduced to Tough's functions in the context of 'what children do with language'. The concept of analysing language functions (as opposed to content) was new to most of the PSTs, and Tough's framework provided an accessible way into this idea. Below are listed her children's language functions:

- Self-maintaining: drawing attention to the self, or criticising others. We explained to the PSTs that it may be useful to think about what they would do if the children on their school visit used too much of this function.

- Directing: telling others what to do, for example in the context of a barrier game.

- Reporting: recounting present or past experiences.

- Reasoning: thinking, explaining or problem-solving.

- Predicting: using evidence to work out what might happen.

- Projecting: putting yourself in someone else's shoes.

- Imagining: using creativity and/or fantasy.

In our discussion with the PSTs we linked these functions to the types of activities they might like to do on their school visits. For example, a classification activity should involve reasoning, or a drama activity would usually include imagining, and often projecting. We also introduced them to Tough's teacher dialogue strategies, listed below:

- Orienting: establishing a relationship and introducing the activity.

- Enabling: building on children's utterances. Tough (1977) describes various ways of achieving this.

- Informing: Giving the children information. We found that it was a challenge for the PSTs to work out what was suitable in this respect.

- Sustaining: using (minimal) feedback to encourage the children to keep talking.

- Concluding: finishing the interaction appropriately.

As well as these functions, we added another one to Tough's teacher dialogue strategies: this was the strategy of 'Instructing', which was not specifically covered by the other five 
functions, but which is an essential part of a teacher's repertoire. We added this function for this reason and because it makes sense in terms of the Speech Function model. (Please see Table 1, below.) The four teacher dialogue strategies of Orienting, Enabling, Informing and Concluding all involve the exchange of information. The Sustaining strategy probably belongs outside the Speech Function model and is best related to an Exchange Structure move such as Backchannel, as it is a dynamic move. Tough's model does not incorporate the exchange of goods and services: adding an Instructing function allows for the teacher telling or suggesting to children what they should do, surely a very common occurrence.

The terms without brackets represent the most common association between Tough's Teacher Dialogue Strategies and Speech Function; the term in brackets represents another possible, but less likely, association.

Armed with the teacher dialogue strategies, the PSTs were able to plan well-structured learning experiences, as judged by their tutors, all of whom were former teachers who were very familiar with the primary school context. As well, the PSTs were able to think in advance of questions they might use with the children.

\section{Furniss and Poulton's framework}

We also introduced the PSTs to Furniss and Poulton's (1991) framework, which is an easily accessible list of various aspects of classroom discourse analysis. The framework includes the following suggestions and questions, some of which overlap with the Derewianka and Tough models:

1. The three-part model of speech IRE/IRF (Initiation ${ }^{\wedge}$ Response $^{\wedge}$ Evaluation/Initiation^ ${ }^{\wedge}$ Response ${ }^{\wedge}$ Feedback), based on Sinclair and Coulthard (1975).

2. Talk ratio: in terms of number of turns produced by the children in comparison to the PST.

3. Elaboration of the topic: turn length and complexity.

4. Peer/peer talk: who talks to whom?

5. Silence: when and why? This includes the concept of 'wait time'.

6. Negotiation: is agreement reached?

7. Feedback: its relationship to the task.

8. Reactions from the children (including Questions).

9. Are all children treated equally?

10. Talk as support for learning (scaffolding).

The PSTs were told that they did not need to respond to all these points in their assignment, but they found them a useful starting point for discussion.

Table 1 Tough's Teacher Dialogue Strategies shown in terms of a Speech Function model

\begin{tabular}{lll}
\hline & Information & Goods and Services \\
\hline Giving & Orienting & \\
& Informing & \\
& Concluding & \\
Demanding & Enabling & Instructing \\
& (Orienting) & \\
\hline
\end{tabular}




\section{Primary knower}

As these were first-year PSTs, it was not considered appropriate to fully introduce them to an Exchange Structure analysis (Berry 1981a,Berry 1981b,Berry 1981c; Martin \& Rose, 2007; Rose \& Martin, 2012). However, the concept of 'primary knower' appealed to them, and they found it easy to grasp. Rose and Martin (2012) describe the 'primary knower' in the following terms: 'the person with the authority to give information is the primary knower in an exchange ... In pedagogic interactions this is usually the parent or teacher...' (p. 296).

We discussed this concept with the PSTs with respect to the relationship they would set up with the children, the type of information that would be exchanged and their preparation in relation to this, and also in regard to "teacher knows the answer" questions. We emphasised that the primary knower rôle is a dynamic one and may change at various points during an interaction. It took time for some PSTs to realise that the children knew more about certain topics than they did themselves.

\section{Interactive trouble}

This concept derives from Conversation Analysis and was introduced to our program through the work of Ludwig and Herschell (1996). There are six main types of 'trouble' that may occur in the classroom:

- Epistemological trouble: when children do not know the answer or what an acceptable answer might be.

- Pedagogical trouble: when the teacher's preferred progression of talk is disrupted.

- Reasoning trouble: when children do not understand the task's purpose or the teacher's logic.

- Theoretical trouble: children's responses do not correspond to the teacher's preferred theories.

- Relational trouble: children do not understand the power and control involved in the relationship between them and the teacher.

- Stylistic trouble: certain forms of expression (for example, standard dialect) are preferred by the teacher, but she/he does not explain why.

The PSTs found the idea of 'trouble' useful when they were analysing what was happening in their transcripts. In fact, they found it so useful that they tended to see 'trouble' everywhere, particularly Pedagogical trouble, which refers to the lesson management breaking down or the lesson not unfolding as expected.

\section{Word classes}

As most of the PSTs arrived at university with very limited or no metalinguistic knowledge, practice on basic concepts, such as word classes, was also incorporated into the unit. This was done in a way that would demonstrate hands-on learning and the types of activities that the PSTs would be able to adapt for their own teaching. Many of these activities were taken from the First Steps materials (Education Department of Western Australia EDWA 1997). One word class was introduced each week, so as not to overload the PSTs with information. The word classes covered were the eight commonly used in traditional grammar, and 
also found in the Australian Curriculum: noun, verb, adjective, adverb, conjunction, preposition, article and pronoun. The PSTs seemed to enjoy the activities, according to tutor observations and student evaluations (See below). Their metalinguistic knowledge was reinforced with a handout in a memorable colour that contained definitions of the clause and of each of the eight word classes. It was suggested that they keep this handout so they could refer back to it in their future Language and Literacy units, thus helping them contextualise this information.

\section{Results}

\section{How the analysis was applied: PSTs' reflections in their assignments}

The following section illustrates how the PSTs were able to apply the analytical frameworks to which they were introduced. We show examples from assignments from the unit that the tutors judged as fulfilling the outcomes of the task at a high level; they are reproduced here with permission. Children were from lower primary school (aged approximately five to eight years). No real names of children are used here. In some cases small corrections have been made to the written expression in the assignments.

\section{Student $A$}

'The language spoken by the children in the first week differed from the language in the second week. One reason for this was because of changes to the Register, which incorporates the Mode, Field and Tenor.

'The Mode, which relates to the textual information, in Week One was Speech as we were exploring Barrier Games. However, its channel changed in Week Two to Drama. Not only did this affect the language between the weeks, but also the turn taking aspect in the activities. For example, in Week One when Alison and Jamie were describing an object to the blindfolded other they took turns in being blindfolded and describing, and they used a lot of content words, particularly adjectives, in their descriptions. (Kylie (K) is the PST):

\section{J: Ooh! It's a prickly thing!}

A: Prickly thing! It might be a plant with prickles on it.

J: Yeah!

A: Is it?

K: Not exactly.

J: And it's pink.

A: Oh, that might be play-doh with pink things in it. Pink play-doh!

J: Not pink play-doh. It's spiky. Ooh, youch, it's a spike.

A: Is it a rose?

J: Yeah! 
'In this brief passage, Jamie used three adjectives to describe the rose to Alison: prickly, pink and spiky. In the drama activity, however, there was not much usage of adjectives, although the potential was there...' [The PST was trying to encourage the children to think what it would be like to live in the town of Hamelin, with all its rats, but found it difficult to get them into role, as they were so excited].

'The Tenor... also differed each week. In Week 1, it was a more formal interaction as we had structured activities to work through. The Drama activity in Week 2 involved a lot of individual expression, offers and ideas by the children. They seemed to interrupt each other and the student teachers a lot more in the Drama visit not only because of their Offers and creative ideas but (also because) it was a little less formal.'

This assignment was highly valued, as it refers to the Register variables and relates them to the activities undertaken at the school. It also connects particular word classes (content words, especially adjectives) to the activities, as part of an analysis of Field, indicating an understanding that as the Field changed from one school visit to the next, the content words changed. The PST has used this analysis to reflect on her practice, realising that the elaborated talk she was hoping to obtain by using the drama mode has not occurred to a great extent.

The assignment also shows knowledge of Speech Function through its mention of Offers (Derewianka 2011, p. 113), and has related this to the Tenor of the two different situations. The writer discusses the dynamics of the interaction in terms of turn-taking (from Furniss and Poulton's framework), indicating that the change in Mode from hands-on activities to drama has affected this. The assignment shows an understanding that Mode can influence Tenor, and that both of these variables are related to conversational dynamics.

\section{Student $B$}

Here the PST describes and justifies his planned activities and how they were linked to Tough's children's language functions.

'The lesson I have planned will help the children to use a wide range of Tough's language functions. The Picture talk activity, which is similar to Newstelling, encourages the children to report on past and present experiences, and also projecting and predicting (e.g. 'How do you think the shells feel when they get washed up on the beach?' 'What do you think would happen if there were a creature living in the shell and it got washed up on the beach?'). Through questioning the children they may use many of Tough's language functions.

'The Classifying activity uses a lot of logical reasoning as to why one card is similar to another. Perhaps it is because of colour or because of size or if it is living or non-living. Furthermore, the card may remind the child of a past experience and the child may then share that experience with the group...'

This assignment was successful in that it clearly relates Tough's children's language functions to the planned activities, and uses this analysis to construct questions that 
the pre-service teacher would ask when at the school. Of the seven of Tough's functions mentioned above, he has planned for four. He has shown an understanding that one activity may involve more than one of the functions, thus enabling him to plan experiences that will enable the children to use a wide range of language.

\section{Student $C$}

This discussion is also about the PST's planned activities:

'The two activities have been chosen to assure that a wide range of Tough's language functions are used by the children. In the first activity, the Barrier Game, the aim is to demonstrate to the children the importance of clear and detailed instructions, along with active listening... The children will need to use Tough's functions to achieve this communication goal. It is expected that the children will use the functions of: self-maintaining, directing, reporting on past and present context and towards logical reasoning. The teacher's role in this activity should be minimal, only using focusing or sustaining questions to maintain the flow of the activity...

'In the second activity, storytelling, the children will have to show a knowledge of narrative structure and the ability to create logical story segments. This will also be achieved with the use of Tough's functions; the children will be encouraged to use: reporting on past and present contexts, towards logical reasoning, predicting, projecting and imagining. In this activity it may be necessary for the teacher to assist the child with questions...'

In a similar way to Student A's assignment, Student B links Tough's language functions with the activities, planning for all seven of the functions over the two school visits, and differentiating the first context from the second. She further goes on to consider the teacher dialogue strategies she will use, reflecting on what rôle she will take up in the interaction. In the first visit she has chosen to focus on the more supportive dialogue strategies, Focussing (which is a type of Enabling) and Sustaining, while in the second visit she realizes that that she may need to take on a more interventionist position.

\section{Student $D$}

Student D's assignment reflects on the visits to the school:

'My activity was for the children to paint a picture that told a story. These would be inspired by cave art and would reflect this by using natural colours such as yellow, red, brown, etc. Firstly I showed the children examples of cave art, then I asked them to create their own pictures, then we shared the stories and had a chance to ask questions about them.

'An example of when I used enabling strategies is when the children were telling their stories. ( $\mathrm{T}$ is the student teacher.)

T: Jack, what do you think will happen to the snake in Alex's story? 
J: I think it'll die because it's getting in the thunder.

T: Mark, do you think that the thunder will kill the snake?

M: Yeah. He'll get electrocuted and go ZAP!

'Here the children had to extend their interpretation of Alex's story and also use the logical reasoning and predicting language functions when asked what they thought would happen to the snake.

'In my lesson I didn't have to use many informing strategies, as the children already seemed to be familiar with the subject, although there were still a few times when I filled in some of the gaps in their knowledge.

T: So guys do you think that the snake will die because it's going in the thunder?

Boys: Yeah

T: What does thunder look like?

J: It's like bright light, like yellow, and it goes ching-ching-ching, like a zigzag.

A: Yeah and it'll fry you like in a fry pan!

[all laugh]

T: Well, thunder is actually the sound that you hear, like the rumbling in the sky. The lightning is the bright light...

'Here the children were confused as to what lightning was and what thunder was. By the end of the lesson they knew the difference and were able to tell me which was which.'

Above, the pre-service teacher has successfully reflected on the Tough teacher dialogue strategies she used (Enabling and Informing) and on their part in the success of her lessons, for example in the language functions she obtained from the children (Reasoning and Predicting). She has also identified some information about vocabulary that she shared with the children: her experience showed that her Informing strategies were successful in introducing some content words to them.

\section{Student $E$}

For this assignment the student teacher worked together with a partner, due to the numbers of children available at the school. This is an example of how the PSTs, like Student A, made use of Furniss and Poulton's framework. Speakers T1 and T2 are the pre-service teachers:

'Furniss and Poulton ask what opportunities were made for peer/peer talk and what type of talk was used. The Lego story created peer/peer talk with limited talk from the teachers. Here is a good example...: 
E: Guys, do you wanna umm, make a really, really big...

I: Yeah

E: ... rock concert story at a fair?

O: Can we make it together?

T1: Yeah, I want you to make it together.

I: Can we join it together?

E: Guys, we're going to...

I: C'mon let's join it together!

E: Like, Izzy, do you wanna make a whole fair. A rock concert fair? And there can be rides and a rock stage...

O: and a roller coaster...

I: That's what I was gonna do...

E: Yeah, that's fun.

T1: That sounds like a great idea.

'The activity Ten Questions is a great example of how a child becomes the expert. In the transcription, Liam becomes the expert because he controls the card that contains the answer.

T1: OK, Eve, your turn first.

E: Does it have legs?

L: Hmmm, no.

T1: Izzy?

I: Ummm, can it fly?

L: No. [laughs]

O: Is it alive?

L: Nooo.

I: Is it a square?

T2: Just wait for your turn, Izzy. You're coming up with some really good questions but each time we have to wait for each person's turn.

T1: OK, my question. Can you find it in the house?

L: Yes.

I: I know! 
T1: OK, so it's not alive and you can find it in your house.

I: Is it a cupboard?

T2: Do you sit on it?

L: No. [laughs]

E: Is it a lamp?

T1: Remember we are asking questions. We need to wait till the end to guess.'

The above examples illustrate how the pre-service teachers encouraged peer/peer talk and are aware of their role in creating it. They have set up a Lego activity where the children have to talk together to decide what to make, and T1's role in the first transcript is just one of giving encouragement, after up to seven turns of the children talking together.

The PSTs also show understanding of the 'primary knower' concept (Berry 1981a, Berry 1981b, Berry 1981c); although the technical term is not used, the word 'expert' is a gloss for it in this context. They have applied to their understanding of their unit material to their practice, in setting up a context where the children can take on the primary knower rôle.

\section{Student $F$}

In this final example, Student F integrates ideas from the different analyses in his reflection:

'Wherever possible, across the course of both school visits, I used supportive, encouraging, probing language strategies aimed at extracting the maximum information and language from the children.

'An analysis of the second school visit transcript revealed a teacher/child talk ratio of 3:2. This surprised me, as I had not expected such a large amount of teacher talk. The barrier games required children to direct each other. The teacher's role had been to orient the children by explaining the activity, answer any questions and then observe children at work. I could have been more effective on the second school visit if I had explained the activity by drawing on the children's prior experience of games like 'Battleship'. My introduction of the barrier games was disjointed and rambling ... As a result, there was some confusion among the children and I found myself constantly interrupting the activities to clarify rules, leading to a higher than expected teacher talk-time. This highlighted how teacher dialogue directly influences children's dialogue'.

Student F produces a high-level discussion that shows a good understanding of the relationship between the teacher's and the children's talk and relates this to the activities and how they were carried out. He uses the concept of talk ratio from Furniss and Poulton to reflect on his rôle in the interaction, showing that the analysis has raised his awareness of this dominance in the dialogue. He reflects on this not only at a holistic level but in relation to individual instances of talk: he regrets needing to interrupt as much as he did, but connects this to his lack of expertise in Tough's Orienting strategy. He has used his knowledge of Orienting in his lesson planning, as the PSTs were encouraged to do, but is critical of the way he has implemented this, relating this to how the activities panned out.

He also displays understanding of other dialogue strategies and language functions (Tough), and has been self-reflective about his ability to capitalize on the children's 
prior knowledge. He shows how the children's functions obtained are related to the activities, with the example of the barrier games 'forcing' Directing. Altogether this is a very good assignment from a first-year PST, showing a high level of reflection as well as an understanding of how the concepts introduced in the unit are interrelated.

\section{Discussion}

What did the PSTs learn? Was it grammar, grammatics or Pedagogical Content Knowledge? Perhaps we could describe it as applied knowledge about language (KAL). Specifically, their work displayed understandings in the following areas:

\section{Register}

The PSTs showed an awareness that the language was related to the context, as introduced to them by Derewianka (1992) questions. Because of the way in which the assignment was conceived, the context was set up so that there would be a contrast between the two school visits. PSTs were able to discuss obvious differences in Field, and how that affected the vocabulary. Mode differences were clearly demarcated by use of barrier games (where the dialogue occurred back-to-back rather than face-to-face) and drama (where the Mode changed completely as the children entered into rôle). The change in Tenor also occurred naturally due to the design of the assignment: in the second visit the participants knew each other better. However, some PSTs, such as Student A, also demonstrated that they could see a relationship between the Mode (drama) and the Tenor.

\section{Functions of discourse moves}

The PSTs found Tough (1977) framework of children's language functions and teacher dialogue strategies very accessible. Some of them, such as Student F, were able to use the dialogue strategies in their planning. One PST, Student D, reflected on successfully using Enabling strategies to encourage children's thinking, and Informing strategies to teach them new vocabulary. The PSTs also demonstrated that they could use their knowledge of children's language functions to plan for a wide range of language use, with Student B planning for the whole range of seven functions over the two visits. The PSTs became aware of how student and teacher discourse is interrelated, with Student F critiquing his own Orienting strategies that led to insufficient student understanding, necessitating his intervention in the dialogue.

The PSTs made use of the concept of Speech Function, both in reflecting on their Questions in general and, in the case of Student A, Offers from the children. Student A understood the place of Offers in the nature of the interactions: the change in Mode to drama caused the children to initiate using Speech Functions such as Offer because they were free to generate their own ideas.

\section{Dynamic aspects of discourse}

Dynamic aspects of discourse such as turn-taking, talk ratios and the amount of peerto-peer talk were the most common aspects taken up from the framework of Furniss and Poulton (1991). These features are not conceptually difficult and are easy to measure, so it is not surprising that PSTs were able to easily take up the ideas and relate them to 
the context. For example, Student E found that the hands-on activity she and her partner designed encouraged peer talk.

Other questions, such as whether all children were treated equally, the ninth point in the framework given above, were certainly considered by the PSTs in their planning, such as by making sure that there was a rôle for each child in the drama activities, but these aspects did not necessarily feature in their reflections.

\section{Knowledge construction}

The primary knower concept (Berry 1981a, Berry 1981b, Berry 1981c) was used in one of the focus assignments (Student E's), although the technical term was not used. The fact that the concept was taken up, but not the terminology, suggests that we were justified in not delving further into Exchange Structure analysis with these first-year PSTs.

In their analysis the PSTs tended to focus on vocabulary rather than grammar, linking the construction of knowledge about a topic to Tough's Informing strategy (for example, Student D). Work on lexical cohesion would have increased their capacity in this area, and this is a system we have introduced PSTs to in later units.

\section{Word classes in context}

The PSTs displayed their knowledge of word classes particularly in relation to content words, in the context of development of the Field (for example, Student A). They found function words more complex, and even the best assignments did not display this, although some (not part of this sample) mentioned prepositions in association with describing location in barrier games.

The most valued assignments produced by the pre-service teachers in this unit displayed a very good developing understanding of the relationship between the language and the context. The school visits and the related assignment provided a context for the PSTs to learn about the functions of language and to relate the Register variables to language elements at the levels of discourse moves, clauses and words. This was a good environment for them to learn about Speech Functions, sentence structure and word classes, as well as the dynamics of conversation.

The PSTs found the two frameworks introduced to them (Tough, and Furniss and Poulton) useful. They thought the Tough model of the functions of teacher and child language was accessible, and used it to reflect on how their talk could influence the children's interactions. They also utilised the input about dynamic aspects of discourse from Furniss and Poulton, enabling them to see some of their data through a quantitative lens.

Berry's concept of primary knower is related to both Field and Tenor, and some PSTs were able to make this connection. For example, Student E found that her activity was instrumental in changing the relationship between the children and pre-service teachers so that the children controlled access to knowledge.

As mentioned above, the concept of interactive trouble (Ludwig and Herschell, 1996) resonated with the PSTs, who tended to find it everywhere in their transcripts, although this is not demonstrated in the examples of quality work shown above.

The PSTs enjoyed the assignment because it allowed them to analyze their own practice, as well as reflect on some of the interesting things that the children said. In some cases they made use of the concepts that were introduced even though they did not use technical 
terms, for example 'relationship' instead of 'Tenor', and 'expert' instead of 'primary knower'. This was entirely appropriate and indicated the developing state of their technical discourse.

While the PSTs displayed that they could look at the functions of language in their own discourse, they did not explore the forms of the utterances themselves to any great extent; this is something that they could have been assisted to investigate further.

Although they had used the KAL we introduced them to in their own reflections, had seen knowledge in action and discussed it every week, the PSTs seemed to need constant reinforcement of this material. Thus, this unit on spoken language needed to be followed by literacy units in which the KAL was discussed in the context of teaching children to read, and particularly to write. Without constant reminders of the need to be specific about linguistic elements, the PSTs tended to revert to making very general statements about language or discussing handwriting and spelling. The value of applying the Mode continuum to program design and introducing PSTs to knowledge about spoken language first, is that PSTs can immediately apply this knowledge to their own practice before they embark on the difficult journey of helping children to become literate. It also places spoken language in its rightful place as the foundation of all other learning.

\section{Conclusions}

This paper has described one way of introducing pre-service teachers to knowledge about language (KAL) in the context of reflecting on their own practice. They found the unit, particularly the school visits, enjoyable, and they could see the relevance of the linguistic knowledge. Their feedback and remarks in the unit evaluation at the end of semester reflect this. For the descriptor 'The unit extended my learning', $80 \%$ of respondents agreed; for 'The unit improved my general skills', $75 \%$ agreed; and for 'The learning materials in this unit were helpful', $74 \%$ agreed.

In answer to the question, 'What were the best aspects of this unit?' the following comments (reproduced verbatim) were provided:

'Visiting the schools and using our spoken language activities with the lower primary students. It was very useful in linking theory to 'real' experience...' (Student 3)

'It went into depth of the different word classes.' (Student 22)

'i like the fact that each week we work on KAL.' (Student 52)

'The tutorials and the refreshing grammar.' (Student 56)

'It helped me learn the word classes and the activities for this were helpful.' (Student 63)

Without contextualisation linguistic knowledge can be seen as somewhat detached from the realities of the classroom. For this reason, we reject behaviourist approaches to learning such concepts as word classes by rote. As mentioned in the introduction to this paper, studies in the Australian and other Anglophone contexts suggest that many pre-service teachers enter university with very little, if any, specific KAL. It is to be hoped that with the advent of the new Australian Curriculum this situation will be ameliorated, in Australia at least, and that this KAL can be incorporated into learning that is meaningful for our future teachers. As universities are changing and have changed their teacher education programs in alignment with the new curriculum, and with the 
likelihood of a national test of the personal literacies and KAL of graduating teachers, the current climate is ripe for research into this area.

\section{Abbreviations}

AC: Australian curriculum; IRE: Initiation^response^evaluation; IRF: Initiation^response^feedback; KAL: Knowledge about language; PSTs: Pre-service teachers.

\section{Competing interests}

The author declares that she has no competing interests.

\section{Acknowledgements}

I would like to thank the teaching teams, schools and pre-service teachers who contributed to the work of this unit. An earlier version of this paper was presented to the $40^{\text {th }}$ International Systemic Functional Linguistics Congress, Guangzhou, PRC, July 2013

Received: 7 January 2015 Accepted: 15 June 2015

Published online: 24 June 2015

\section{References}

Berry, M. 1981a. Systemic Linguistics and discourse analysis: A multi-layered approach to Exchange Structure. In Studies in Discourse Analysis, ed. M Coulthard and M Montgomery, 120-45. London: Routledge \& Kegan Paul.

Berry, M. 1981b. Polarity, ellipticity, elicitation and propositional development, their relevance to the well-formedness of an exchange. Nottingham Linguistic Circular 10(1): 36-63.

Berry, M. 1981c. Towards layers of Exchange Structure for directive exchanges. Network 2: 23-32.

Derewianka, B. 1991. Exploring How Texts Work. Sydney: PETA.

Derewianka, B. 1992. Assessing Oral Language. In Language Assessment in Primary Schools, ed. B Derewianka, 68-102. Sydney: Harcourt Brace.

Derewianka, B. 2011. A New Grammar Companion for Teachers. Sydney: PETA.

Education Department of Western Australia (EDWA). 1997. Writing Resource Book. Melbourne: Rigby Heinemann.

Freebody, P, and C Ludwig. 1998. Talk and literacy in schools and homes. Canberra: Commonwealth of Australia.

Furniss, E, and M Poulton. 1991. Classroom Discourse: Organising Opportunities for Talk". In The Literacy Agenda, ed. E Furniss and P Green, 17-34. Melbourne: Eleanor Curtain.

Halliday, MAK. 1975. Learning How to Mean: Explorations in the Development of Language. London: Edward Arnold.

Harper, H, and J Rennie. 2009. 'I had to go out and get myself a book on grammar': A study of pre-service teachers' knowledge about language. Australian Journal of Language and Literacy 32(1): 22-37.

Jeurissen, M. 2012. 'Perhaps I didn't really have as good a knowledge as I thought I had'. What do primary teachers know and believe about grammar teaching? Australian Journal of Language and Literacy 35(3): 301-16.

Ludwig, C, and P Herschell. 1996. Talking - Our way into literacy. Melbourne: Curriculum Corporation.

Macken-Horarik, M. 2012. Why school English needs a 'good enough' grammatics (and not more grammar). Changing English: Studies in Culture and Education 19(2): 179-94.

Martin, JR. 2007. Construing knowledge: a functional linguistic perspective. In Language, Knowledge and Pedagogy, ed. F Christie and JR Martin, 34-64. London: Continuum.

Martin, JR, and D Rose. 2007. Working with Discourse: Meaning Beyond the Clause. London: Continuum.

Myhill, D, S Jones, and A Watson. 2013. Grammar matters: How teachers' grammatical knowledge impacts on the teaching of writing. Teaching and Teacher Education 36: 77-91.

Painter, C. 1985. Learning the Mother Tongue. Geelong, Vic:: Deakin University Press.

Rose, David, and JR Martin. 2012. Learning to Write, Reading to Learn: Genre, Knowledge and Pedagogy in the Sydney School. London: Equinox.

Sinclair, J, and M Coulthard. 1975. Towards an Analysis of Discourse: The English Used by Teachers and Pupils. Oxford: Oxford University Press.

Thwaite, A. 2008. Australian Review of Applied Linguistics 31(2): 18.1-18.15.

Thwaite, A. and Rivalland, J. 2009. How can analysis of classroom talk help teachers reflect on their practices? Australian Journal of Language and Literacy 32(1): 38-54.

Tough, J. 1977. Children's Use of Language: Listening to Children Talking, 79-83. London: Schools Council.

Ventola, E. 1987. The Structure of Social Interaction. London: Pinter. 